\title{
The Impact of Mobile TradeManager on Fashion Product Sales: From Usability Perspective
}

\author{
Zilong Liu, ${ }^{1,2}$ Zhenhua Liu, $^{1,3}$ and Qingfei Min ${ }^{1}$ \\ ${ }^{1}$ Faculty of Management and Economics, Dalian University of Technology, Dalian 116025, China \\ ${ }^{2}$ School of Management Science \& Engineering, Dongbei University of Finance and Economics, Dalian 116025, China \\ ${ }^{3}$ Global Institute of Management and Economics, Dongbei University of Finance and Economics, Dalian 116025, China
}

Correspondence should be addressed to Zhenhua Liu; liuzhenhua@dufe.edu.cn

Received 30 April 2014; Revised 9 July 2014; Accepted 11 July 2014; Published 20 July 2014

Academic Editor: Xiaohang Yue

Copyright (C) 2014 Zilong Liu et al. This is an open access article distributed under the Creative Commons Attribution License, which permits unrestricted use, distribution, and reproduction in any medium, provided the original work is properly cited.

\begin{abstract}
The competition in fashion and textiles (FTs) industry is strong. Enterprises have to compete at all levels and need to adapt to the mobile commerce (MC) context. Mobile TradeManager (MTM) is a typical MC application and good use of it will facilitate the sales of FTs products. Plenty of prior studies on MC were developed to discuss the subjective beliefs. Motivated by the research that appeals for more attention to IT artifact itself, this paper integrates the system usability of MC into the behavioral model. To this end, the purpose of this study is twofold: (a) to identify the impact of MTM usability on consumers' online shopping behavior of FTs production, and (b) to explore and understand how usability of MTM could be improved. Data analysis, based on a survey of 837 MTM users, reveals that perceived entertainment, MTM system usability, subjective norm, and consumer's self-efficacy significantly affect individual's intention to use MTM. Meanwhile, it is revealed that MTM usability is a joint function of mobile device's system performance, WAP website's design, and the characteristics of wireless communication networks.
\end{abstract}

\section{Introduction}

The fashion and textiles (FTs) industry plays an important role in the economic growth of a developing country, and it experienced fast development over the past decade. Meanwhile, the past decade has witnessed huge changes in information technology field. The mobile trend of e-commerce, which can be considered as m-commerce (MC), is a typical case in point. Any transaction "conducted through a variety of mobile equipment over a wireless telecommunication network" can be considered as MC [1]. Nowadays, more and more users conduct transactions via their mobile phones. And one of the most popular transactions is the buying and selling of fashion products. Mobile TradeManager, a mobile instant messaging (MIM) application, significantly contributes for the development of fashion products transactions. TradeManager is a free instant messenger for the members of http://www.taobao.com/, which is an online shopping web portal dedicated to all the Chinese people. Due to the strong competition in the fashion industry and the fast development of new products, the enterprises need to compete at all levels and to penetrate the new markets in order to avoid their products "out of date." Meanwhile, they should reach their end consumers as soon as possible. Mobile TradeManager (MTM) is such a platform which can push the information of fashion products to the mobile users even when they are on the move. It allows communication between the buyers and the sellers. However, in practice, not all the mobile phone users would like to use mobile TradeManager on their devices. According to the International Telecommunication Union, the number of mobile accounts reached over 6.8 billion worldwide in 2013 and the number reached over 1.2 billion in China [2]. The large number of mobile subscribers provides a great opportunity for the development of MC and fashion industry. Therefore, it is necessary and valuable to explore what factors affect consumers' intention to use MTM to purchase FTs products.

The paper first identifies the factors affecting consumer's intention of adopting mobile TradeManager to by FTs products and then analyzes what influences the MTM's usability. 
A comprehensive research model is presented and subsequently validated by using the data collected from a survey of 837 MTM users in Mainland China. This is followed by the presentation of the research results, discussion of the theoretical and managerial implications, and the recommendations for future research.

\section{Literature Review}

2.1. Theoretical Foundation. As noticed and stated by many studies [3-5], the most frequently employed theory in IS acceptance field is TAM. Although the TAM related studies significantly contribute to the understandings of various types of technologies acceptance in many different contexts, few of them have made great contributions to the theoretical development. Indeed, as indicated by many researchers, the homogeneity in the large multitude of studies investigated that TAM is very likely to weaken the field of technology adoption research [3-5]. As such, Benbasat and Barki suggested researchers to start with theory of reasoned action (TRA) or theory of planned behavior (TPB) by including salient beliefs such as IT artifact related variables [5]. One of the motivations of the study on which this paper is based, applying TPB, is to answer this call. With two decades of research findings, it is clear that three factors are found to be important predictors of behavioral intention, namely, subjective norm, attitude, and perceived behavioral control, in many contexts. As indicated by prior studies, TPB also has its limitations as it bears the shortcoming of excluding the IT artifact itself. The focus of this paper is not on examining the relationships between these constructs and behavioral intention, but on discovering "salient beliefs" and overcoming the shortcomings of the model. Prior research in usability studies suggested that usability-based models can be more directly tied to the system design characteristics [6]. In other words, usability is a basic characteristic of the IT artifact. Therefore, involving usability into the research model is a great way to improve the validity of TPB.

2.2. Usability and Technology Acceptance. Usability has been intensively studied in human-computer interaction (HCI) field. However, most of the studies were conducted to investigate web- and computer-based software or technologies. The results of such studies may not be applicable when studying WAP and mobile devices based MC applications due to the unique characteristics of the mobile technology. Therefore, the studies exploring the usability of MC emerged and most of them were conducted in the recent five years. For example, Venkatesh and Ramesh [6] examined the usability of web versus wireless site and found that successful web presence did not automatically lead to a successful wireless web presence; Wei and Ozok [7] studied the usability features required by the mobile air ticketing commerce; BalagtasFernandez and Hussmann [8] presented a framework to help developers in preparing the usability of mobile system; other studies $[9,10]$ tested usability issues of mobile ICT for hospitals or clinics; Kim [11] explored time-based usability to study human mobile-web interactions.
More recent studies on the usability of mobile device based applications show that researchers have realized the importance of usability issues in MC context. However, it is noticeable that few papers mentioned above have integrated the usability studies with the technology acceptance literature. In other words, usability literature has focused on the IT artifact itself, and scant attention has been paid to the behaviors and attitudinal/behavioral beliefs. Interestingly, as stated earlier, the opposite appears in technology acceptance literature. Actually, lack of correspondence in studying usability and technology acceptance is not a phenomenon existing only in MC context. The authors conducted a search for papers addressing both the usability and technology acceptance issues published during the period between 2000 and 2010, only 18 articles on this subject were identified in the top eight journals in the IS field (MIS Quarterly, Decision Sciences, Decision Support Systems, IEEE Transactions on Engineering Management, Information \& Management, Information Systems Research, Journal of Management Information Systems, Management Science). Therefore, the authors believe that it is contributive to integrate these two streams.

\section{Research Model and Hypotheses}

3.1. Perceived Entertainment. The main purpose of the hedonic information system is to provide the fun-aspect value to users; that is, the more enjoyable using the system is, the more likely users will take a positive attitude towards it. Actually, perceived entertainment has been involved in several theories. The two most influential ones are flow theory [12] and theory of motivation [13]. The former indicates that if the system is leisure-oriented, individuals would enjoy themselves intensively during the using process. The latter defines the perceived entertainment as "the extent to which the activity of using the computer is perceived to be enjoyable in its own right, apart from any performance consequences that may be anticipated." The two theories stipulate the perceived entertainment in the same way. As found by many studies, "time flies when you're having fun" [14-16]. Therefore, the more fun individuals expect to experience when using the MC application (MTM), the more likely they will use it. The effect of the perceived entertainment on consumer intention to use MC has been examined by several studies, for example, [17-19]. Thus the following hypothesis is formulated.

(H1) The perceived entertainment significantly influences the behavioral intention to adopt the hedonic MC applications.

3.2. Subjective Norm. The subjective norm is one's perception that "most people who are important to him/her thinks he/she should or should not perform the behavior in question" [20]. It has been examined extensively in the technology acceptance literatures. Due to its popularity, Schepers and Wetzels [21] conducted a meta-analysis of research on TAM to explore the role of this construct and revealed that the subjective norm has significant influence on the behavioral intention. Accordingly, it is believed that whether or not an individual 
will adopt an MC application is affected by the opinions from important others, especially for the applications (such as MTM) that require mutual involvement.

(H2) The subjective norm significantly influences the behavioral intention to adopt the hedonic MC applications.

3.3. Self-Efficacy. The self-efficacy is an important construct in the social psychology and frequently examined as a significant antecedent of people's determination of the computer use. Bandura [22] defined self-efficacy as "people's judgments of their capabilities to organize and execute courses of action required to attain designated types of performances," and it is the belief that one has the capability to perform a particular behavior [23]. Computer self-efficacy is defined as "a judgment of one's capability to use a computer" [23]. Research in various domains has confirmed the role of selfefficacy as a precursor of behavioral decisions. For example, Hsu and Chiu [24] found that the Internet self-efficacy was a potentially important factor in explaining consumers' ecommerce use; Kim et al. [25] confirmed that the selfefficacy significantly affect the employee's intention to adopt hotel information system; Yi and Hwang [26] discussed the factors affecting the actual use of web-based information systems and highlighted the role of self-efficacy. Accordingly, individual's judgment of their abilities to competently use the MC applications (self-efficacy perceptions about MC) will impact their intention of the MC acceptance. Therefore, the higher the individual's self-efficacy is, the more likely he/she will adopt the MC.

(H3) The self-efficacy significantly influences individual's behavioral intention to adopt the hedonic MC applications.

3.4. System Usability of MC. The usability has been intensively studied in the human computer interaction interface design filed, both from the holistic perspectives [27] and from some specific (component) perspectives [28]. With the development of the MC, the usability studies in the traditional human-computer interaction field were adapted to improve the features of various $\mathrm{MC}$ applications, for example, $[6,7,10$, 11]. The usability testing of the MC applications is considered to be a challenge due to the mobile context, the devices, and and so forth, [29]. Coursaris and Kim [30] conducted a qualitative review of the empirical mobile usability studies and revealed three core dimensions to measure the usability of MC applications, which are efficiency, effectiveness, and satisfaction. These three dimensions are empirically validated in the $\mathrm{MC}$ context, and therefore they are considered the first three choices to measure the usability of MTM usage. Meanwhile, it is noticed that the learnability was a dimension examined as frequently as effectiveness. In order to minimize the chance of omitting the valuable dimensions, items related to the learnability are also included in this study. Another aspect requiring the attention is the security of systems. Whether it is safe to use an MC application is an issue concerned by the majority of the mobile phone users. Research has revealed that the consumer's trust of the secure data transmission in the $\mathrm{MC}$ context was significantly lower than in the traditional e-commerce context [31]. Some researchers argued that security can stimulate the MC development [32]. Therefore, the security of the IT artifact itself should be tested. In conclusion, this paper tests the usability of the MC applications from the five attributes, namely, effectiveness, efficiency, satisfaction, learnability, and security.

Based on the above discussion, it is clear that a system scores high on the five usability attributes and is of great quality and will make the MC application easy to use. Thus, the consumer's attitude toward such system is more likely to be positive and the propensity to use such an application will be increased. Prior studies were conducted to discover the role of the website usability [33-35] and found that the usability of the website (website quality) had a significant influence on the purchase intention of the online shopper. Accordingly, the usability of an MC application should positively affect consumer's intention to use.

Meanwhile, as aforementioned, pursuing the perceived entertainment is consumer's expectation to which they can experience fun in the process of using the system. Hence, only the applications with great efficiency, effectiveness, and security will be more likely to provide an enjoyable experience for the users. Therefore, the following hypotheses were developed.

(H4) The system usability of MTM significantly influences individual's behavioral intention.

(H5) The system usability of MTM significantly influences individual's perceived entertainment.

By reviewing and summarizing the prior studies, and taking the unique characteristics of mobile applications, three main factors affecting usability of MC were identified, namely, performance of the mobile devices, wireless communication network, and content/navigation of the WAP sites.

3.4.1. Performance of the Mobile Devices. Mobile devices are the platform for the MC applications. Compared with the computers, that is, desktop and laptop, the mobile devices have several impersonal limitations, such as small screen size, small keyboard, poor data entry and data retrieval capabilities, poor data processing capabilities, and poor memory and limited battery power. Sears and Arora [36] even regard these limitations as the most important user-related obstacles to accept the MC. For example, the inconvenience when entering data and the long-waiting time are only a challenge for the user's patience, but also a sign of the low efficiency and effectiveness of the MC. This will further reduce the user's satisfaction. In addition, many MC applications (mobile shopping, mobile TV, etc.) are power-consuming. Thus, users with high-performance mobile devices are more likely to find that the $\mathrm{MC}$ is usable. That is, the performance and characteristics of mobile devices will affect the usability of the $\mathrm{MC}$ applications conducted on them.

(H6) The performance of the mobile devices significantly affects the usability of MC applications. 
3.4.2. WAP Web Sites. Due to the limitations of the mobile devices, it is not possible for the wireless sites of the MC to include all the detail contents offered by e-commerce sites. Therefore, how to provide the features that the consumers need on such a small screen becomes an issue of vital importance. This can be examined in two aspects: content presentation and content navigation.

Content has been identified as an important characteristic in both web and wireless sites use [6]; however, the presentation of content matters more to wireless sites. As indicated by prior studies [7, 37], "one-to-one content translation from e-commerce to $\mathrm{m}$-commerce is not an optimal solution." Condos et al. [38] evaluated the usability of two UK portals and identified that content unsuitable for the WAP environment was one of the key issues. Wei and Ozok also argued that it was the usefulness of features rather than the number of features provided that was critical for the MC success [7]. Therefore, the presentation of the content will influence the usability of the MC applications.

Since the wireless sites are not a translated version of the web sites, content navigation is definitely different. Another issue raised by Condos et al. [38] is "ong lists" with too many options, which will lower the usability. Studies showed that some users will never scroll down the navigation page for the other available links. Furthermore, Venkatesh et al.s study indicated that the ability to locate relevant content quickly was the most important factor for the use of the wireless site [6]. Therefore, the navigation of the content will influence the usability of the MC applications.

(H7) The characteristics of the WAP web sites significantly affect the usability of the MC applications.

3.4.3. Characteristics of Wireless Communication Network. The ubiquitous available wireless communication network is the prerequisite for the success of the MC because it is the channel through which the MC is conducted. Since $\mathrm{MC}$ is an emerging business model, the supporting facility including the wireless communication network is not yet perfect. Nowadays, many users have experienced the instability of wireless connection, poor data transmitting speed, poor wireless internet access, and so forth. As known to all, the advantages of the MC applications primarily lie in that they allow users to deal with time-sensitive tasks, for example, emergency medical treatment, traffic rescue, and so forth. Consequently, the data transmission speed, wireless network stability, and coverage rate of the network are of great importance. These aspects are closely associated with the MC usability, since they are the key factors determining whether the users' tasks can be achieved with efficiency, effectiveness and satisfaction. Meanwhile, the influence of the characteristics of wireless networks exerting on the design of the WAP web sites is self-evident. The content and navigation of the wireless web sites has to be designed in consideration of the characteristics (including various inconvenience) of the wireless networks. Therefore,

(H8) the characteristics of the wireless network significantly affect the usability of MC applications;
(H9) the characteristics of the wireless network significantly affect the design of WAP web sites.

Based on the above analysis, the research model is depicted in Figure 1, and the structural model is proposed as shown in the following:

$$
\begin{gathered}
\mathrm{BI}=\alpha_{0}+\alpha_{1} * \mathrm{PEN}+\alpha_{2} * \mathrm{SN}+\alpha_{3} * \mathrm{SE}+\alpha_{4} * \mathrm{USA}+\varepsilon_{1}, \\
\mathrm{PEN}=\beta_{0}+\beta_{1} * \mathrm{USA}+\varepsilon_{2}, \\
\mathrm{USA}=\gamma_{0}+\gamma_{1} * \mathrm{PMD}+\gamma_{2} * \mathrm{WAP}+\gamma_{3} * \mathrm{NET}+\varepsilon_{3}, \\
\mathrm{WAP}=\lambda_{0}+\lambda_{1} * \mathrm{NET}+\varepsilon_{4} .
\end{gathered}
$$

Note the following: BI: behavioral intention; PEN: perceived entertainment; SN: subjective norm; SE: self-efficacy; USA: usability of system; WAP: WAP web sites; NET: wireless networks; PMD: performance of mobile device.

\section{Research Method}

4.1. Instruments. Most of the items were adapted from previously validated instruments. Behavioral intention was measured with three items from Davis' study [39]; subjective norms were measured with the three items developed by Ajzen [40]; perceived entertainment was measured using the instruments in Dickinger and Stangl [41]; usability of system was adapted from Abran et al. [42] and Nielsen [43]; self-efficacy was measured using the construct developed by Schwarzer [44]; performance of mobile device was adapted from Peter's research [45]; WAP web sites was developed by the authors; wireless networks was adapted from the research of George et al. [46].

As the current study was conducted in a Chinese speaking context and the original measures of the studied constructs were developed in English, the survey instrument was translated from English into Chinese. First the instruments were translated from the original English into Chinese and subsequently back-translated into English by another bilingualist. The back-translated text was then compared with the original text. Where discrepancies existed, the Chinese version and the original English version were examined and, if necessary, the final translation was amended.

Based on the research model and the scale, the measurement model was proposed as shown in

$$
\begin{aligned}
& \text { ItemBI }_{i}=\eta_{1 i} * \mathrm{BI}+\sigma_{1 i}, \quad(i=1, \ldots, 3), \\
& \text { ItemSE }_{j}=\eta_{2 j} * \mathrm{SE}+\sigma_{2 i}, \quad(j=1, \ldots, 3), \\
& \text { ItemPEN }_{k}=\eta_{3 k} * \mathrm{PEN}+\sigma_{3 k}, \quad(k=1, \ldots, 3), \\
& \text { ItemSN }_{m}=\eta_{4 m} * \mathrm{SE}+\sigma_{4 m}, \quad(m=1, \ldots, 3), \\
& \text { ItemUSA }_{n}=\eta_{5 n} * \mathrm{USA}+\sigma_{5 n}, \quad(n=1, \ldots, 9), \\
& \text { ItemNET }_{o}=\eta_{6 o} * \mathrm{NET}+\sigma_{6 o}, \quad(o=1, \ldots, 3), \\
& \text { ItemPMD }_{p}=\eta_{7 p} * \mathrm{PMD}+\sigma_{7 p}, \quad(p=1, \ldots, 7), \\
& \text { ItemWAP }_{q}=\eta_{8 q} * \mathrm{WAP}+\sigma_{8 q}, \quad(q=1, \ldots, 12) .
\end{aligned}
$$




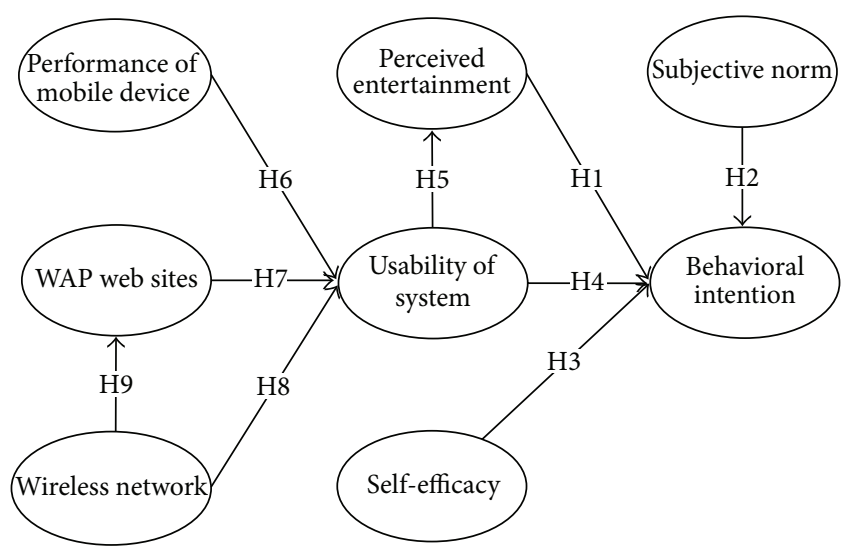

Figure 1: Research model.

Note the following: ItemBI ${ }_{i}$ : item $i$ of BI scale; ItemSE $E_{j}$ item $j$ of SE scale; ItemPEN ${ }_{k}$ : item $k$ of PEN scale; ItemSN ${ }_{m}$ : item $m$ of SN scale; ItemUSA $A_{n}$ : item $n$ of USA scale; ItemNET ${ }_{o}$ : item $o$ of NET scale; ItemPMD $p$ : item $p$ of PMD scale; ItemWAP : $^{\prime}$ item $q$ of WAP scale.

4.2. Data Collection. Data were collected by means of online questionnaire survey. A total of 837 valid questionnaires were collected from Mainland China. Respondents were asked to complete the questionnaire that gathered the information regarding the demographic variables, the use of MTM, and their feelings about the using process. Most of the items used in this study were adapted from previous studies with appropriate modifications to make them specifically relevant to MTM usage. A seven-point Likert scale anchored by "strongly disagree" (1) to "strongly agree" (7) was used to examine individuals' response.

The demographic characteristics of respondents are shown in Table 1 . Results show that most of the respondents $(64.9 \%)$ are male, and $82.2 \%$ of all the respondents have received college or university education. Results also show that $33.5 \%$ respondents aged at $18-25$ and another $37.4 \%$ aged at $26-30$. About a third (33.4\%) of the users have an experience of using MTM for 1-2 years.

\section{Data Analysis}

5.1. Reliability and Validity Assessment. Cronbach $\alpha$ coefficient was used to assess the reliability of the constructs. As shown in Table 2, these alphas range from 0.803 to 0.925 that reached a level commonly accepted as a high satisfactory for multi-item scales [47]. These values show good reliability of scales.

Validity concerns the soundness of the variables. It includes the content validity and construct validity. Since the items of our questionnaire were adapted from previous empirical studies and expert opinions were included, the items are believed to be of content validity.

Construct validity refers to whether a scale measures a variable of interest. It is evaluated by the convergent validity
TABLE 1: Demographic profile.

\begin{tabular}{lcc}
\hline Measure & Frequency & Percent \\
\hline Gender & 543 & \\
Male & 294 & $64.9 \%$ \\
Female & & $35.1 \%$ \\
Education & 78 & \\
$\quad$ Secondary certificate & 215 & $9.31 \%$ \\
college graduate & 473 & $25.7 \%$ \\
University graduate & 71 & $56.5 \%$ \\
Master degree and above & & $8.48 \%$ \\
Age & 380 & \\
18-25 & 313 & $33.5 \%$ \\
$26-30$ & 197 & $37.4 \%$ \\
31-40 & 47 & $23.5 \%$ \\
40+ & & $5.61 \%$ \\
MTM experience & 119 & \\
1 year- & 147 & $27.0 \%$ \\
1-2 years & 47 & $33.4 \%$ \\
2-3 years & 127 & $10.7 \%$ \\
3 years+ & 837 & $28.9 \%$ \\
\hline Total & & $100 \%$ \\
\hline
\end{tabular}

TABLE 2: Item loading, AVE, and CR.

\begin{tabular}{lcccc}
\hline Construct & Cronbach $\alpha$ & Item loadings & AVE & CR \\
\hline PMD & 0.862 & $0.698-0.789$ & 0.552 & 0.747 \\
PEN & 0.896 & $0.800-0.901$ & 0.860 & 0.899 \\
SN & 0.803 & $0.685-0.886$ & 0.615 & 0.826 \\
WAP & 0.925 & $0.746-0.806$ & 0.609 & 0.926 \\
NET & 0.868 & $0.712-0.934$ & 0.709 & 0.878 \\
USA & 0.888 & $0.688-0.842$ & 0.583 & 0.893 \\
BI & 0.880 & $0.823-0.876$ & 0.706 & 0.878 \\
SE & 0.908 & $0.863-0.885$ & 0.769 & 0.909 \\
\hline
\end{tabular}

PMD: performance of mobile device; PEN: perceived entertainment; SN: subjective norm; WAP: WAP web sites; NET: wireless networks; USA: usability; BI: behavioral intention; SE: self-efficacy.

and discriminant validity. The SEM (structural equation modeling) method of the confirmatory factor analysis (CFA) was employed to evaluate the construct validity. As shown in Table 1, most of the item loadings are over 0.70, each AVE (average variance extracted) exceeds 0.50 , and the values of the CR (composite reliability) are over 0.70 . All these values show that the questionnaire is of good convergent validity [48].

If the two constructs do not overlap greatly, the discriminant validity is presumed to exist between them. In the present paper, discriminant validity is validated by comparing the square root of AVE and the correlations between constructs. Table 3 shows the correlation matrix for each pair of constructs. Diagonal elements in the correlation of constructs matrix are the square root of the average variance extracted. The comparison shows that the discriminant validity of the questionnaire is acceptable. 
TABLE 3: Correlations between constructs.

\begin{tabular}{llllllll}
\hline Construct & PMD & PEN & SN & WAP & NET & USA & BI \\
\hline PMD & $\mathbf{0 . 7 4 3}$ & & & & & & \\
PEN & 0.503 & $\mathbf{0 . 9 2 7}$ & & & & & \\
SN & 0.410 & 0.546 & $\mathbf{0 . 7 8 4}$ & & & & \\
WAP & 0.686 & 0.554 & 0.498 & $\mathbf{0 . 7 8 0}$ & & & \\
NET & 0.675 & 0.473 & 0.380 & 0.728 & $\mathbf{0 . 8 4 2}$ & & \\
USA & 0.658 & 0.727 & 0.535 & 0.713 & 0.640 & $\mathbf{0 . 7 6 4}$ & $\mathbf{0 . 8 4 0}$ \\
BI & 0.430 & 0.643 & 0.584 & 0.493 & 0.375 & 0.682 & 0.650 \\
SE & 0.364 & 0.514 & 0.470 & 0.337 & 0.230 & 0.860 & $\mathbf{0 . 8 7 7}$ \\
\hline
\end{tabular}

Correlation is significant at the 0.01 level (2-tailed).

TABLE 4: Fit indexes.

\begin{tabular}{|c|c|c|c|c|c|c|c|c|c|}
\hline & $\chi^{2} / \mathrm{df}$ & RMSEA & GFI & AGFI & NFI & RFI & IFI & TLI & CFI \\
\hline Recommended value & $<5$ & $<0.08$ & $>0.90$ & $>0.80$ & $>0.90$ & $>0.90$ & $>0.90$ & $>0.90$ & $>0.90$ \\
\hline Value in this study & 3.473 & 0.05 & 0.884 & 0.865 & 0.919 & 0.911 & 0.941 & 0.935 & 0.941 \\
\hline
\end{tabular}

5.2. Model Testing. AMOS 17.0 was used to test the research model. The goodness-of-fit is shown in Table 4. As shown, most of the indexes meet the recommended value except GFI (slightly below the benchmark). The fit measures indicated an acceptable overall fit of the model. Figure 2 shows the model estimates. All the standardized path coefficients are significant, indicating that all the hypotheses proposed in the research are supported.

\section{Discussion and Implication}

The structural equation model shown in Figure 2 indicates that the individual's behavioral intention is jointly determined by the subjective norm, perceived entertainment, self-efficacy, and system usability. Among these constructs, the individual's perception of their abilities (self-efficacy) to competently use the MC applications is the key influencing factor. The results support the author's argument that the performance of the mobile devices, design of WAP web sites (including navigation and content present), and the characteristics of wireless communication networks significantly affect the usability of the MC application. Accordingly, to encourage the consumers to use the applications, the primary task is to make good use of individual's self-efficacy. Therefore measures should be taken to highlight the entertainment and the usability of the MC applications. Meanwhile, emphasizing the influence from important others (subjective norm) is also a good way to encourage the acceptance of MC.

Specifically, self-efficacy in this study is one's perception about whether he/she has the capacity to use MIM. Individuals with higher self-efficacy judgments believe that using MTM is not difficult for them. According to the demographic statistics of this study, $87.5 \%$ of the respondents are aged at 18-35, and most of them are well educated. Therefore, this cluster of users perceived higher self-efficacy and learning to use MTM is an easy task for them. The results might suggest that the new MC applications should be oriented to young people. At the same time, the MC providers should educate

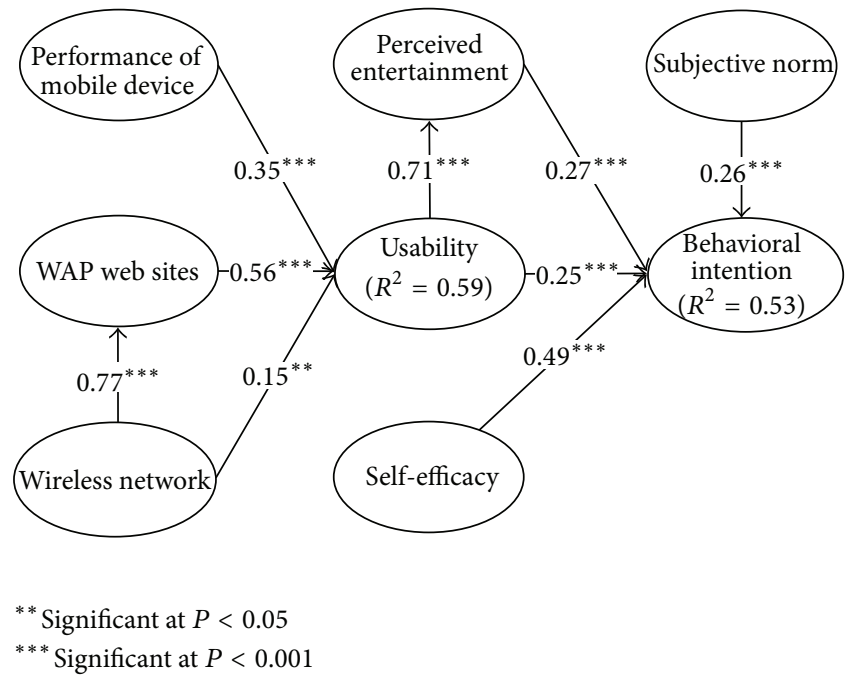

Figure 2: Structural equation model.

their potential consumers about how to use the applications and make users feel easy and comfortable to conduct the operations.

The effects of subjective norm have been extensively examined and confirmed by the research both in the traditional IS field and in the emerging MC domain. Therefore, emphasizing the influence of the subjective norm is of great importance. Measures should be taken to encourage the MC users to introduce their friends to use such applications.

The usability of MC the applications (MTM) is the focus of this paper. On one hand, the usability is integrated into the research model and identified as a significant factor in influencing user's behavioral intention. It is tested in regards of efficiency, effectiveness, learnability, security, and satisfaction. The positive path coefficient $(\beta=0.25)$ indicates that these five dimensions are seriously considered by the $\mathrm{MC}$ users. When using the MC, whether the application can 
enable the users to finish their tasks (utilitarian or hedonic) with sound effectiveness and efficiency in a safe way definitely affects the user's determination of MC use.

On the other hand, the antecedents of usability are explored. The path diagram shown in Figure 2 demonstrates that the WAP web site is the most important one $(\beta=0.56)$. This finding conforms to the prior studies which emphasized the importance of the content presentation and content navigation $[6,7,38]$. To improve the usability of the MC, only important and personalized features should be offered. Meanwhile, the features must be structured reasonably. Offering the users a quick indication or an informative summary of the content that they want is suggested as a good measure.

The performance of the mobile devices is found to be influential in the MC usability $(\beta=0.35)$. Compared with the computer, the weakness of mobile devices is obvious. However, the limitations do not necessarily prevent individuals from using the $\mathrm{MC}$ as long as the wireless web is reasonable structured and the content is well designed. For example, when designing the MC applications, developers should minimize the data entrance by users and provide menu options (which should not be too long) instead. The content should be displayed in one screen as clearly as possible, as indicated by the prior research [38]. By these measures, operations on the mobile devices will not be complex and power consuming. And of course, device providers have to keep improving the performance and functions of mobile devices.

The characteristics of wireless communication network also have a significant positive effect on the usability of the MC. Limited by bandwidth, the speed of wireless network connection and transmission is not possible as fast as wired network. Thus the effectiveness and efficiency of the MC usability are influenced. However, the impact that the wireless network exerts on system usability is the weakest among the three antecedents $(\beta=0.15)$. The reasons for this result are twofold. First, the wireless communication network in China has been developed very fast in recent years, and the infrastructure construction has been strengthened. Second, the results indicate that the consumers are concerned more about the characteristics of the WAP web sites and the mobile devices.

\section{Conclusion}

To examine the impact of mobile TradeManager usability on c FTs products sales is the purpose of this paper. Previous cognitive-based technology acceptance studies are criticized for ignoring the characteristics of IT artifact itself. This paper explores the characteristics of artifact under investigation (MTM) and investigated its influence on consumer's intention to buy FTs product from the usability perspective. Both subjective and objective characteristics of MTM were examined. According to the results revealed by the data collected from 837 respondents, perceived entertainment, usability of MC applications, subjective norm, and self-efficacy are main determinants affecting user's purchase intention to buy FTs product. Meanwhile, factors influencing the usability of MC were explored. Results indicated that the usability can be improved by reasonably structuring the WAP web sites (in terms of navigation and content present), enhancing mobile device performance and further improving the quality of wireless communication networks. By conducting this study, we hope to provide guidance for enterprises in FTs industry to reach their end customers more effectively.

\section{Conflict of Interests}

The authors declare that there is no conflict of interests regarding the publication of this paper.

\section{Acknowledgments}

This work is sponsored by National Natural Science Foundation of China (no. 71301021 and no. 71072108), China Postdoctoral Science Foundation (2014M551098), Scientific Research Foundation of Liaoning Provincial Education Department (no. W2013201), and DUFE Excellent Talents Project (DUFE2014R28).

\section{References}

[1] K. C. C. Yang, "Exploring factors affecting the adoption of mobile commerce in Singapore," Telematics and Informatics, vol. 22, no. 3, pp. 257-277, 2005.

[2] Ministry of Industry and Information Technology of the People's Republic of China, "Monthly statistic report of telecommunication industry for the month of December, 2013," http://www.miit.gov.cn/n11293472/n11293832/n11294132/ n12858447/15858096.html.

[3] M. D. Williams, Y. K. Dwivedi, B. Lal, and A. Schwarz, "Contemporary trends and issues in IT adoption and diffusion research," Journal of Information Technology, vol. 24, no. 1, pp. $1-10,2009$.

[4] L. Zhenhua, M. Qingfei, and J. Shaobo, "A comprehensive review of research in IT adoption," in Proceedings of the International Conference on Wireless Communications, Networking and Mobile Computing (WiCOM '08), L. Cuthbert and Z. T. Wang, Eds., pp. 1-5, Dalian, China, October 2008.

[5] I. Benbasat and H. Barki, "Quo vadis, TAM?" Journal of the Association for Information Systems, vol. 8, no. 4, pp. 211-218, 2007.

[6] V. Venkatesh and V. Ramesh, "Web and wireless site usability: Understanding differences and modeling use," MIS Quarterly, vol. 30, no. 1, pp. 181-206, 2006.

[7] J. Wei and A. Ozok, "Development of a web-based mobile airline ticketing model with usability features," Industrial Management and Data Systems, vol. 105, no. 9, pp. 1261-1277, 2005.

[8] F. Balagtas-Fernandez and H. Hussmann, "A methodology and framework to simplify usability analysis of mobile applications," in Proceedings of the 24th IEEE/ACM International Conference on Automated Software Engineering (ASE '09), pp. 520-524, 2009.

[9] D. Svanaes, O. A. Alsos, and Y. Dahl, "Usability testing of mobile ICT for clinical settings: methodological and practical challenges," International Journal of Medical Informatics, vol. 79, no. 4, pp. e24-e34, 2010. 
[10] Y. Dahl, O. A. Alsos, and D. Svanæs, "Fidelity considerations for simulation-based usability assessments of mobile ICT for hospitals," International Journal of Human-Computer Interaction, vol. 26, no. 5, pp. 445-476, 2010.

[11] Y. B. Kim, "Real-time analysis of time-based usability and accessibility for human mobile-web interactions in the ubiquitous internet," Journal of Universal Computer Science, vol. 16, no. 15, pp. 1953-1972, 2010.

[12] M. Csikszentmihalyi, Flow: The Psychology of Optimal Experience, Harper and Row, New York, NY, USA, 1990.

[13] F. D. Davis, R. P. Bagozzi, and P. R. Warshaw, "Extrinsic and intrinsic motivation to use computers in the workplace," Journal of Applied Social Psychology, vol. 22, no. 14, pp. 1111-1132, 1992.

[14] A. M. Sackett, T. Meyvis, L. D. Nelson, B. A. Converse, and A. L. Sackett, "You're having fun when time flies: the hedonic consequences of subjective time progression," Psychological Science, vol. 21, no. 1, pp. 111-117, 2010.

[15] J. G. Voet and D. Voet, "Time flies when you're having fun," Biochemistry and Molecular Biology Education, vol. 37, no. 1, p. 1, 2009.

[16] J. A. Danckert and A. A. Allman, “Time flies when you're having fun: Temporal estimation and the experience of boredom," Brain and Cognition, vol. 59, no. 3, pp. 236-245, 2005.

[17] J. W. Ong, Y.-S. Poong, and T. H. Ng, "3G services adoption among university students: diffusion of innovation theory," Communications of the IBIMA, vol. 3, pp. 114-121, 2008.

[18] C. H. Liao, C. W. Tsou, and M. F. Huang, "Factors influencing the usage of $3 \mathrm{G}$ mobile services in Taiwan," Online Information Review, vol. 31, no. 6, pp. 759-774, 2007.

[19] I. Lee and J. Kim, "Use contexts for the mobile internet: a longitudinal study monitoring actual use of mobile internet services," International Journal of Human-Computer Interaction, vol. 18, no. 3, pp. 269-292, 2005.

[20] M. Fishbein and I. Ajzen, Belief, Attitude, Intention, and Behavior: An Introduction of Theory and Research, Addison-Wesley, Reading, Mass, USA, 1975.

[21] J. Schepers and M. Wetzels, "A meta-analysis of the technology acceptance model: Investigating subjective norm and moderation effects," Information \& Management, vol. 44, no. 1, pp. 90103, 2007.

[22] A. Bandura, Social Foundations of Thought and Action, Prentice Hall, Englewood Cliffs, NJ, USA, 1986.

[23] D. R. Compeau and C. A. Higgins, "Computer self-efficacy: development of a measure and initial test," MIS Quarterly, vol. 19, no. 2, pp. 189-210, 1995.

[24] M. Hsu and C. Chiu, "Internet self-efficacy and electronic service acceptance," Decision Support Systems, vol. 38, no. 3, pp. 369-381, 2004.

[25] T. T. Kim, Y. K. Suh, G. Lee, and B. G. Choi, "Modelling roles of task-technology fit and self-efficacy in hotel employees' usage behaviours of hotel information systems," International Journal of Tourism Research, vol. 12, no. 6, pp. 709-725, 2010.

[26] M. Y. Yi and Y. Hwang, "Predicting the use of web-based information systems: self-efficacy, enjoyment, learning goal orientation, and the technology acceptance model," International Journal of Human Computer Studies, vol. 59, no. 4, pp. 431-449, 2003.

[27] R. Agarwal and V. Venkatesh, “Assessing a firm's web presence: a heuristic evaluation procedure for the measurement of usability," Information Systems Research, vol. 13, no. 2, pp. 168-186, 2002.
[28] W.-F. Brinkman, R. Haakma, and D. G. Bouwhuis, "The theoretical foundation and validity of a component-based usability questionnaire," Behaviour and Information Technology, vol. 28, no. 2, pp. 121-137, 2009.

[29] D. Zhang and B. Adipat, "Challenges, methodologies, and issues in the usability testing of mobile applications," International Journal of Human-Computer Interaction, vol. 18, no. 3, pp. 293308, 2005.

[30] C. K. Coursaris and D. J. Kim, "A qualitative review of empirical mobile usability studies," in Proceedings of the 12th Americas Conference on Information Systems (AMCIS '06), pp. 2873-2879, Acapulco, Mexico, August 2006.

[31] A. A. Ozok and J. Wei, "User perspectives of mobile and electronic commerce with a usability emphasis," in Proceedings of the ISOne World Conference, Las Vegas, Nev, USA, 2004.

[32] L. Palen and M. Salzman, "Beyond the handset: designing for wireless communications usability," ACM Transactions on Computer-Human Interaction, vol. 9, no. 2, pp. 125-151, 2002.

[33] Y. J. Wang, S. Hong, and H. Lou, "Beautiful beyond useful? The role of web aesthetics," Journal of Computer Information Systems, vol. 50, no. 3, pp. 121-129, 2010.

[34] C. Jones and S. Kim, "Influences of retail brand trust, off-line patronage, clothing involvement and website quality on online apparel shopping intention," International Journal of Consumer Studies, vol. 34, no. 6, pp. 627-637, 2010.

[35] L. F. Yeh, E. M. Y. Wang, and S. L. Huang, "A study of emotional and rational purchasing behavior for online shopping," in Online Communities and Social Computing, Proceedings, D. Schuler, Ed., pp. 222-227, Springer, Berlin, Germany, 2007.

[36] A. Sears and R. Arora, "Data entry for mobile devices: an empirical comparison of novice performance with Jot and Graffiti," Interacting with Computers, vol. 14, no. 5, pp. 413-433, 2002.

[37] V. Venkatesh, V. Ramesh, and A. P. Massey, "Understanding usability in mobile commerce," Communications of the ACM, vol. 46, no. 12, pp. 53-56, 2003.

[38] C. Condos, A. James, P. Every, and T. Simpson, “Ten usability principles for the development of effective WAP and $\mathrm{m}$ commerce services," Aslib Proceedings, vol. 54, no. 6, pp. 345355, 2002.

[39] F. D. Davis, "Perceived usefulness, perceived ease of use, and user acceptance of information technology," MIS Quarterly, vol. 13, no. 3, pp. 319-339, 1989.

[40] I. Ajzen, "The theory of planned behavior," Organizational Behavior and Human Decision Processes, vol. 50, no. 2, pp. 179211, 1991.

[41] A. Dickinger and B. Stangl, "Website performance and behavioral consequences: a formative measurement approach," Journal of Business Research, vol. 66, no. 6, pp. 771-777, 2013.

[42] A. Abran, A. Khelifi, W. Suryn, and A. Seffah, "Usability meanings and interpretations in ISO standards," Software Quality Journal, vol. 11, no. 4, pp. 325-338, 2003.

[43] J. Nielsen, Usability Engineering, Academic Press, San Diego, Calif, USA, 2004.

[44] R. Schwarzer, "Optimism, vulnerability, and self-beliefs as health-related cognitions: a systematic overview," Psychology and Health, vol. 9, pp. 161-180, 1994.

[45] T. Peter, Mobile Commerce: Technology, Theory, and Applications, Idea Group Publishing, Hershey, Pa, USA, 2002.

[46] B. George, F. Sarah, M. Gary, and P. Michael, "Improving mobile internet usability," in Proceedings of the 10th International 
Conference on World Wide Web, pp. 673-680, New York, NY, USA, 2001.

[47] J. C. Nunally, Psychometric Theory, McGraw-Hill, New York, NY, USA, 1978.

[48] C. Fornell and D. F. Larcker, "Evaluating structural equation models with unobservable variables and measurement error," Journal of Marketing Research, vol. 18, no. 2, pp. 39-50, 1981. 


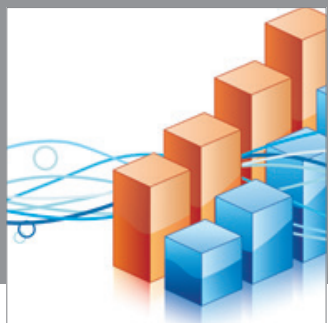

Advances in

Operations Research

mansans

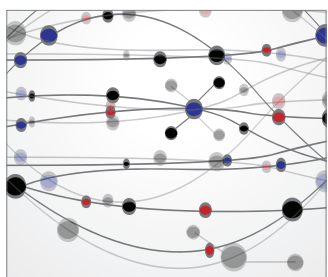

The Scientific World Journal
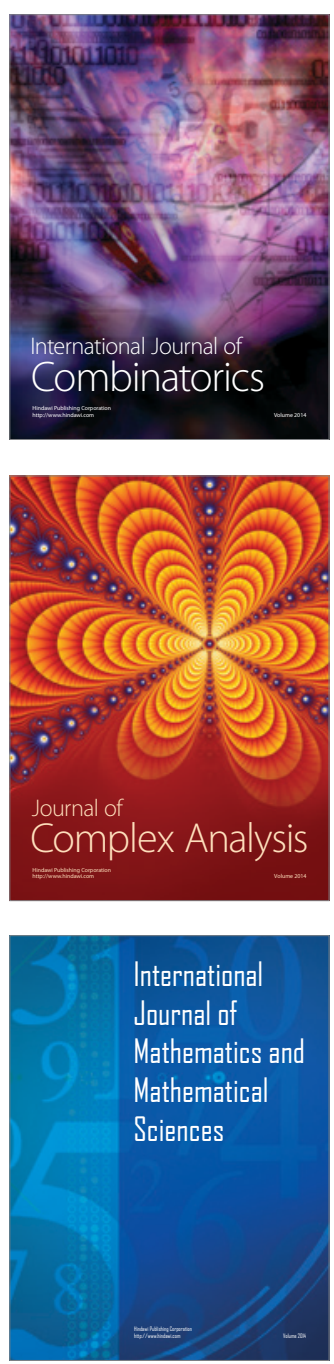
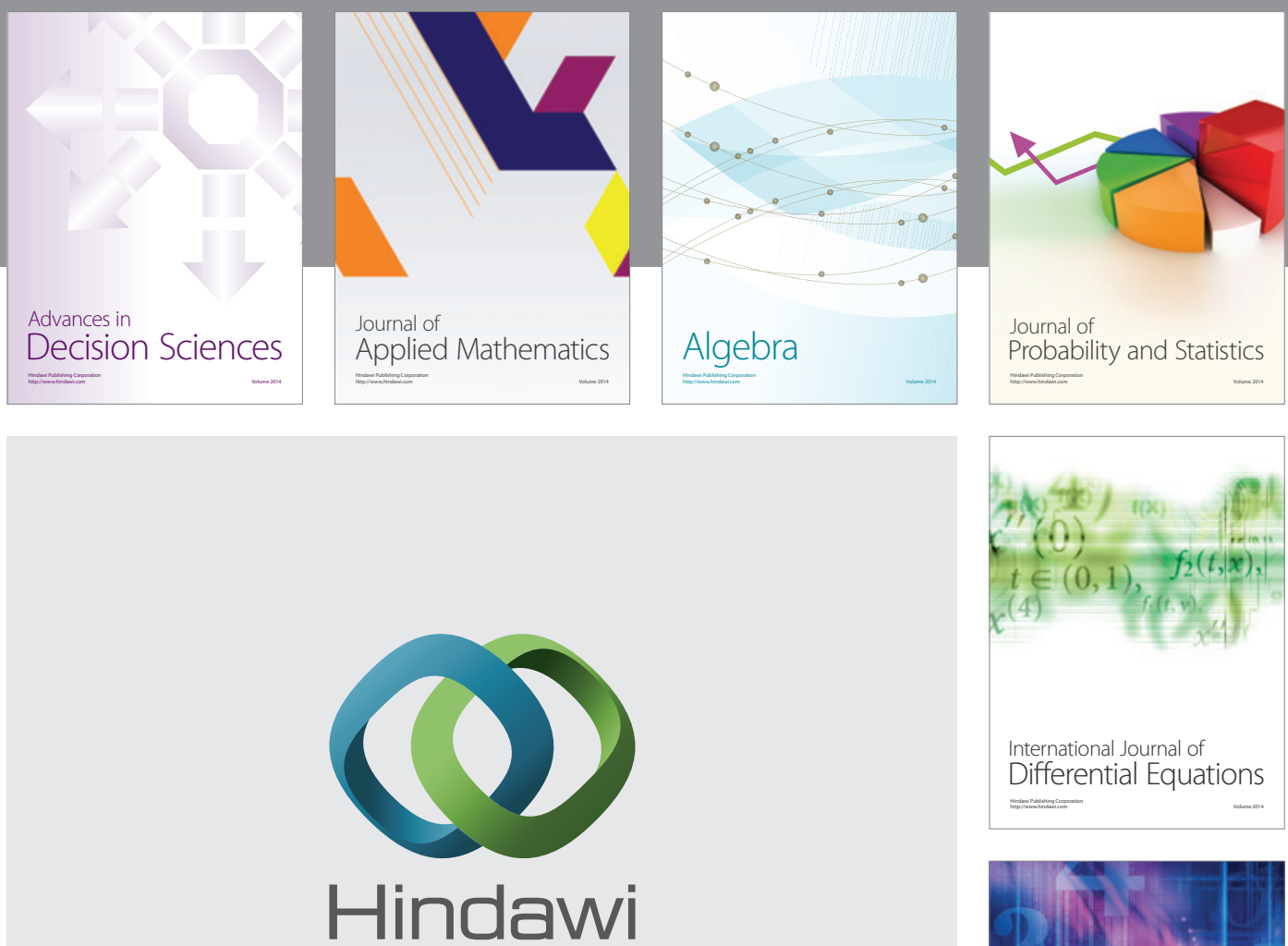

Submit your manuscripts at http://www.hindawi.com
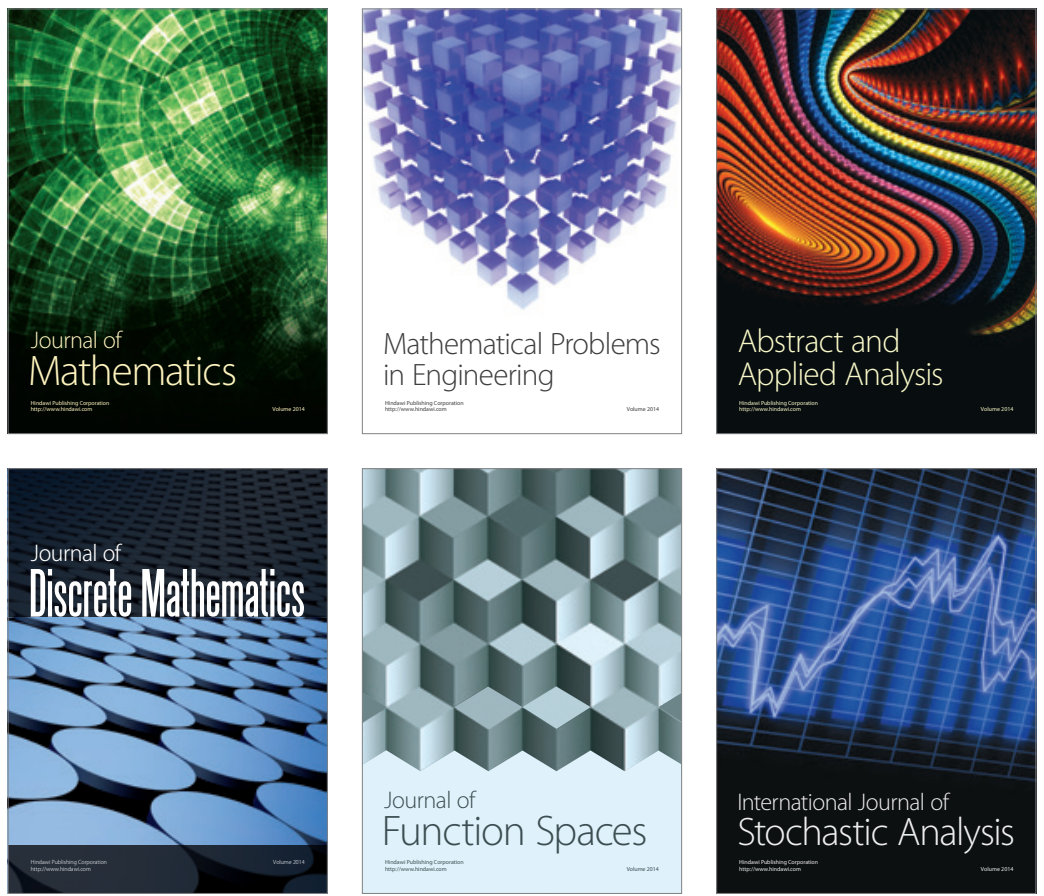

Journal of

Function Spaces

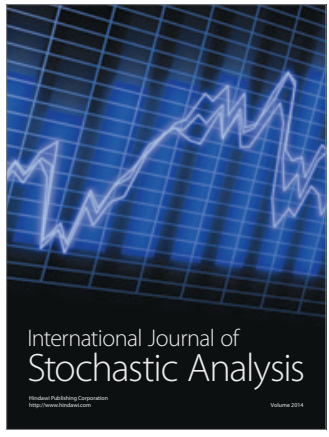

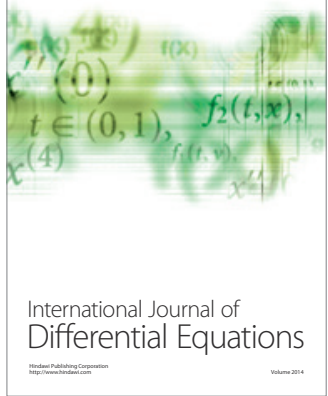
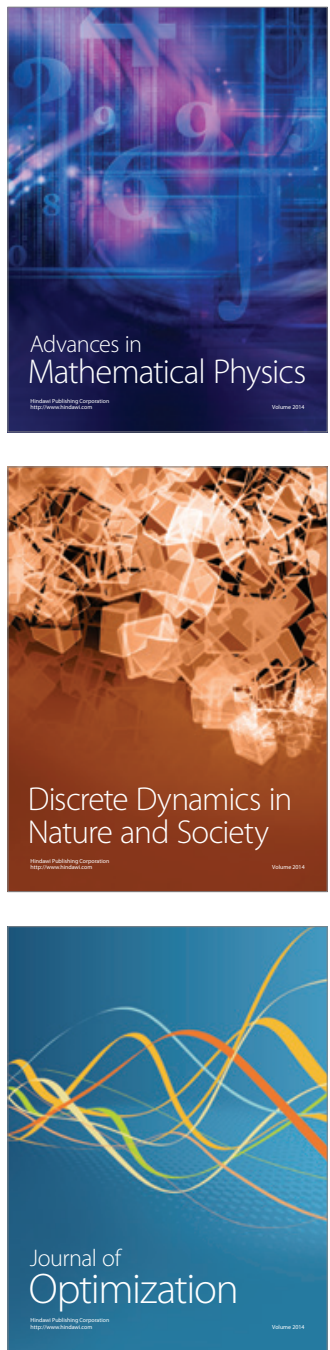